\title{
EFFECTS OF TRANSCUTANEOUS ELECTRICAL NERVE STIMULATION (TENS) ON PATIENTS WITH ACUTE LOW BACK PAIN
}

\author{
Ahmed B ${ }^{1}$, Alam S 2 , Rashid I ${ }^{3}$, Rahman N ${ }^{4}$, Rahman A ${ }^{5}$, Uddin T ${ }^{6}$, Azad GN ${ }^{7}$
}

\begin{abstract}
Background: Acute low back pain (LBP) affects a significant proportion of the population. Transcutaneous electrical nerve stimulation (TENS) was introduced more than 30 years ago as an adjunct to the pharmacological management of pain. However, despite its widespread use, the usefulness of TENS in LBP is still controversial.

Introduction: LBP is a common problem in Bangladesh. Acute LBP is usually defined by a period of complaints of LBP of six weeks or shorter. TENS may improve acute LBP.
\end{abstract}

Objective: To evaluate the effectiveness of TENS on acute LBP and also to ensure the patients wellbeing by shortening recovery time who have acute LBP.

Methods: A prospective study was carried out in the Department of Physical Medicine and Rehabilitation, Bangubandhu Sheikh Mujib Medical University (BSMMU), Dhaka, Bangladesh, from July 2008 to December 2008. The patients were divided into two groups (A and B). Patients of Group A (30 patients) were treated with TENS, Non-steroidal anti-inflammatory drugs (NSAIDs) and activities of daily living (ADLs) instruction. Patients of group B (28 patients) were treated with NSAIDs and ADLs instructions.

Results: A total of 58 Patients of acute LBP were included in this study. The mean age of the patients was $38.5 \pm 9.01$ years. Main causes of pain were muscle strain $(39.65 \%)$, nonspecific LBP $(\mathbf{2 2 . 4 1 \% )}$, prolapsed lumber intervertebral disc $(17.24 \%)$, lumbar spondylosis $(13.79 \%)$ and sciatica $(6.91 \%)$. After treatment the result was compared and student's ' $t$ ' test was done to see the level of significance. Method was found significant after treatment $(\mathbf{p}<0.05)$. Twenty four $(80 \%)$ patients were improved in group A and 18 (64.28\%) patients in group B. Patient compliances of group A were better than that in group $B$.

Conclusion: Effect of TENS on patients with acute low back pain is beneficial.
Keywords: Transcutaneous electrical nerve stimulation (TENS), acute low back pain (LBP)

\section{Introduction}

Acute low back pain is the fifth most common reason for all physician visits ${ }^{1}$. Acute LBP is usually defined by a period of complaints (LBP) of six weeks or shorter ${ }^{2}$. Low back pain is the most common reason that adults seek out patients' physical therapy ${ }^{3}$. Low back pain is an uncomfortable sensation in the lumbar and buttock region originated from neurons near or around the spinal canal that are injured or irritated by one or more pathologic process ${ }^{4}$. In United State approximately $90 \%$ of persons in the working population have back pain every year ${ }^{5}$.In United Kingdom back pain is the second most common cause of physical disability after cardio vascular disease ${ }^{5}$. Even in Bangladesh it is the commonest cause of disability. Causes of Acute LBP are due to back strain, acute disc herniation, osteoarthritis, spinal stenosis, spondylolysthesis, ankylosing spondylitis, infection and malignancy ${ }^{6}$. In case of acute LBP $5-10 \%$ of cases become chronic ${ }^{7}$. The impact of surgery on the management of acute LBP is $l_{0}{ }^{8}$. For the majority of non surgical patients, activity modification, analgesics, muscle relaxant, education, spinal manipulation therapy and epidural injections are recommended to shorten recovery time and as symptomatic therapy 9 . In contrast with these well established concepts TENS therapy can be used in the management of acute LBP. For, TENS is the appropriate treatment for acute and chronic low back pain which can not be treated less expensively, more safely or more effectively by other means ${ }^{10}$. For more than four decades TENS has been applied in the treatment of acute and chronic pain syndrome ${ }^{11,12}$. Role of other therapeutic modality (Short wave diathermy, ultrasound therapy) in management of LBP in aspect of our country has been studied, which are not sufficient enough in management

1. Dr Badrunnese Ahamed MBBS, MCPS, Medical Officer, Department of Physical Medicine \& Rehabilitation, BSMMU, Dhaka; 2. Lt Col Md Shafiqul Alam MBBS, MS, Classified Specialist in Orthopaedic Surgeon, CMH, Dhaka; 3. Dr Imamur Rahasid MBBS, MCPS, Medical Officer, Department of Physical Medicine \& Rehabilitation, BSMMU, Dhaka; 4. Dr Nadia Rahman MBBS, MCPS, Medical Officer, Department of Physical Medicine \& Rehabilitation, BSMMU, Dhaka; 5. Dr Azizur Rahman MBBS, FCPS, Consultant Physician, Adhunik Sadar Hospital, Kishoregonj; 6. Dr Md Taslim Uddin MBBS, FCPS, Professor Department of Physical Medicine \& Rehabilitation, BSMMU, Dhaka; 7. Dr Golam Nabi Azad MBBS, MCPS, Medical Officer, Department of Physical Medicine \& Rehabilitation, BSMMU, Dhaka. 
of acute LBP and no such study has done yet in role of electrotherapy (TENS) on evaluation of acute LBP in our country. The aim of this study is to evaluate the effectiveness of TENS on acute LBP which is a very common problem in day to day practices and also to establish TENS as a treatment modality along the conventional one. To ensure the patients' wellbeing by shortening recovery time, who have acute LBP and they can get back to their active state of life as soon as possible.

\section{Materials and Methods}

This prospective randomized study was carried out in the Department of Physical Medicine and Rehabilitation (PM\&R), Bangabandhu Sheikh Mujib Medical University (BSMMU), Dhaka from July 2008 to December 2008. Patients having acute LBP were selected from the Department of PM\&R, who were referred from various out patients Department of BSMMU and also from general practitioners outside the Hospital. On arrival at the Department detailed history was taken and clinical examination and necessary investigations were carried out properly. Seventy patients were selected for this study according to the following criteria.

\section{Inclusion criteria}

- Patients of both sexes of aged between 20-60 years

- Patients having LBP for 6 weeks or less

- No current treatments has been used for pain medications (as prescribed by the physician)

- Patients who are able to complete the questionnaire Exclusion criteria

- Pain duration more than 06 weeks

- Patients with any inflammatory low back pain

- Patient with other complications like cauda equina syndrome, caries spine, malignancy, pregnant women - Patients with cardiac pace maker

Patients in group-A were treated with TENS, NSAIDs and Instructions of Activities of daily living (ADL). Patients in group-B were treated with NSAIDs and ADL instructions. Patients in group A were treated with low frequency $(0.5$ to $10 \mathrm{~Hz})$ high intensity TENS for 30 minutes for consecutive 15 days. The electrodes were placed paravertebrally at the low back region.

Melzack \& Wall described the "Gate control theory"; according to that (a) Cells within the substantia gelatinosa are stimulated by both small diameter nociceptive and large diameter sensory neurons; (b) these cells serve as gate by inhibiting the relaying of nociceptive information to the brain if non painful sensory stimuli present. Low frequency-high intensity TENS stimulate central nervous system (CNS) to secrete body's own natural morphine like substances known as endorphin. These endorphins work as similar manner to conventional narcotics to provide the body with overall pain relief. It also raises the pain threshold level ${ }^{10}$.
Aceclofenac (100 mg) was given twice daily after meal along with Capsule Omeprazole $(20 \mathrm{mg}$ ) twice daily before meal for gastrointestinal support for fifteen consecutive days. ADLs were advocated verbally and some of them were physically demonstrated to all patients when required. Those were to avoid prolonged standing, to avoid prolonged sitting, to use plain firm bed, to use soft single pillow, to lie down in supine position, to be cautious during get in and get out of bed, to use high commode, to have working surface of adequate height of $5-10 \mathrm{~cm}$ below the elbow, to avoid stooping, to use long levered cleaner during sweeping, to avoid tight fitting garments, to avoid high heeled shoes, to avoid weight lifting or to lift with caution to keep back straight during activity, to avoid twisting and to drive in a comfortable position with adequate height.

\section{Measures of Variables}

Demographic variables: Age, Sex, Occupation and Socio-economic condition

Outcome Measures:

- Subjective pain intensity ${ }^{13}$ : No pain=O, Mild=I, Uncomfortable $=2$, Severe $=3$, Unbearable $=4$

- Visual Analogue Scale (VAS): VASs are $10 \mathrm{~cm}$ lines anchored at the ends by words that defined bounds of various pain dimensions. The patients were asked to place a vertical mark on the scale to indicate the level of intensity of his or her pain ${ }^{13}$.

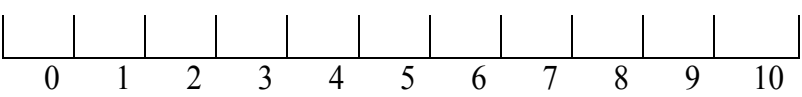

\section{No pain $=0 \quad$ Maximum intensity of pain $=10$}

Tenderness Index ${ }^{14}: \mathrm{O}=$ No pain, $\mathrm{I}=$ Describes pain, $2=$ Patient winces, $3=$ Patient winces and withdraw the affected part, $4=$ The patient will not allow the joint to be touched

- Disability due to pain $^{14}$ : None $=\mathrm{O}, \mathrm{Slight}=\mathrm{l}$, Moderate $=2$, Necessary aid $=3$, Dependence $=4$

- Spinal mobility Index ${ }^{15}: \mathrm{SLR}=$ Straight Leg

Raising LT $=$ Left,

Normal $=90^{\circ}$ RT $=$ Right

Modified Schober's test : $6-7 \mathrm{~cm}=$ Normal

$<5 \mathrm{~cm}$ indicative of organic spinal pathology

Patients were first examined at day 1 (pretreatment) and at day 15 (post treatment) follow up and the outcomes were recorded in the assessment data shit. All the outcome assessment data were analyzed by using the computer. The numerical data were analyzed statistically by using the SPSS-package program (verstion-10) for windows. Student's ' $t$ ' test was done to evaluate the level of significance. The results were expressed as mean \pm standard deviation (SD) and $\mathrm{p}<0.05$ was considered as the level of significance. All categorical data were expressed in percentage (\%) and frequency (f). 


\section{Results}

A total 70 patients of acute LBP were included in this study. But 12 patients were dropped out from the study because they could not attend or could not follow the instructions. So, total 58 patients followed the treatment. In group A 30 patients and in group B 28 patients were included. The mean age of the patients was $38.5 \pm 9.01$ years, mean weight of the patients was $62.18 \pm 6.45$ killogram. Mean duration of symptoms of the patients was $12.17 \pm 5.11$ days. In the present series maximum number (22 patients) belonged to age group 31-40 years (table-I). Male to female ratio of patient was 1.4:1. Though pin point diagnosis of the patients with acute LBP was difficult, it was tried to make a differential diagnosis. Among the study patients $(n=58) 23$ patients $(39.65 \%)$ were diagnosed as muscle strain and other diagnoses are shown in Table-III.

Table-I: Distribution of the patients as per age group

\begin{tabular}{|c|l|l|l|}
\hline $\begin{array}{c}\text { Age group } \\
\text { (in years) }\end{array}$ & $\begin{array}{l}\text { Group-A } \\
\mathrm{f}(\%)\end{array}$ & $\begin{array}{l}\text { Group-B } \\
\mathrm{f}(\%)\end{array}$ & $\begin{array}{l}\text { Total } \\
\mathrm{f}(\%)\end{array}$ \\
\hline $20-30$ & $02(6.67)$ & $05(17.86)$ & $07(12.08)$ \\
\hline $31-40$ & $12(40)$ & $10(35.71)$ & $22(37.93)$ \\
\hline $41-50$ & $10(33.3)$ & $08(28.57)$ & $18(31.03)$ \\
\hline $51-60$ & $06(20)$ & $05(17.86)$ & $11(18.96)$ \\
\hline Total & $30(100)$ & $28(100)$ & $58(100)$ \\
\hline
\end{tabular}

Table-II: The Occupations of study population

\begin{tabular}{|l|l|l|l|}
\hline Occupation & $\begin{array}{l}\text { Group-A } \\
\text { f }(\%)\end{array}$ & $\begin{array}{l}\text { Group-B } \\
\mathbf{f}(\%)\end{array}$ & $\begin{array}{l}\text { Total } \\
\mathbf{f}(\mathbf{\%})\end{array}$ \\
\hline Service holder & $12(40)$ & $08(28.57)$ & $20(34.48)$ \\
\hline Day labourer & $05(16.67)$ & $06(21.43)$ & $11(18.96)$ \\
\hline House wife & $04(13.33)$ & $06(21.43)$ & $10(17.24)$ \\
\hline Student & $05(16.67)$ & $04(14.28)$ & $09(15.52)$ \\
\hline Business man & $03(10)$ & $02(07.14)$ & $05(08.62)$ \\
\hline Driver & 00 & $02(07.14)$ & $02(03.45)$ \\
\hline Others & $01(3.33)$ & 00 & $01(1.72)$ \\
\hline Total & $30(100)$ & $28(100)$ & $58(100)$ \\
\hline
\end{tabular}

Table-III: Distribution of patients according to diagnosis

\begin{tabular}{|l|l|l|l|}
\hline Diagnosis & $\begin{array}{l}\text { Group-A } \\
\mathbf{f}(\mathbf{\%})\end{array}$ & $\begin{array}{l}\text { Group-B } \\
\mathbf{f}(\%)\end{array}$ & \multicolumn{1}{|l|}{$\begin{array}{l}\text { Total } \\
\mathbf{f}(\%)\end{array}$} \\
\hline Muscle strain & $11(36.67)$ & $12(42.86)$ & $23(39.66)$ \\
\hline Non-specific & $07(23.33)$ & $06(21.43)$ & $13(22.41)$ \\
\hline PLID & $04(13.33)$ & $06(21.43)$ & $10(17.24)$ \\
\hline $\begin{array}{l}\text { Lumbar } \\
\text { spondylosis }\end{array}$ & $05(16.67)$ & $03(10.71)$ & $08(13.79)$ \\
\hline Sciatica & $03(10)$ & $01(3.57)$ & $04(06.90)$ \\
\hline Total & $30(100)$ & $28(100)$ & $58(100)$ \\
\hline
\end{tabular}

In the present study $37.5 \%$ patients were from poor class, $60.71 \%$ patients were from middle class and $1.79 \%$ patients were from rich class of socio-economic status. In the present series, intensity of pain in both the groups was similar before treatment according to criteria of pain measurement scoring system. Mean values were nearly same in both the groups. There were no significant differences in pretreatment assessment scores between the groups. After consecutive 15 days of treatment, significant improvement of pain in low back region were observed in both the groups but more on group-A (Table-IV).

Table-IV: Comparative improvement between groups on 1 st day (D1) and 15th day (D15)

\begin{tabular}{|c|c|c|c|}
\hline Parameter & $\begin{array}{c}\text { Group A } \\
(\mathbf{n = 3 0 )} \\
\text { Mean } \pm \text { SD }\end{array}$ & $\begin{array}{c}\text { Group B } \\
(\mathbf{n = 2 8 )} \\
\text { Mean } \pm \text { SD }\end{array}$ & p value \\
\hline Subject pain intensity & & & \\
\hline Pretreatment score $\mathrm{D}_{1}$ & $3.15 \pm 0.48$ & $3.27 \pm 0.66$ & 0.503 \\
\hline Post treatment score $\mathrm{D}_{15}$ & $1.35 \pm 0.68$ & $2.11 \pm 0.67$ & 0.015 \\
\hline Pain score (VAS) & & & \\
\hline Pretreatment score $\mathrm{D}_{1}$ & $7.15 \pm 0.75$ & $7.11 \pm 0.83$ & 0.880 \\
\hline Post treatment score $\mathrm{D}_{15}$ & $5.25 \pm 0.16$ & $6.11 \pm 0.75$ & 0.011 \\
\hline Tenderness index & & & \\
\hline Pretreatment score $\mathrm{D}_{1}$ & $2.90 \pm 0.30$ & $2.72 \pm 0.46$ & 0.167 \\
\hline Post treatment score $\mathrm{D}_{15}$ & $1.30 \pm 1.08$ & $1.88 \pm 0.58$ & 0.047 \\
\hline Disability due to pain & & & \\
\hline Pretreatment score $\mathrm{D}_{1}$ & $2.10 \pm 0.64$ & $2.44 \pm 0.61$ & 0.101 \\
\hline Post treatment score $\mathrm{D}_{15}$ & $0.90 \pm 0.71$ & $1.61 \pm 0.50$ & 0.001 \\
\hline Spinal SLR & & & \\
\hline Pretreatment score $\mathrm{D}_{1}$ & $82.00 \pm 10.56$ & $82.22 \pm 10.03$ & 0.948 \\
\hline Post treatment score $\mathrm{D}_{15}$ & $85.50 \pm 7.59$ & $86.66 \pm 8.40$ & 0.656 \\
\hline Modified Schober's Test & & & \\
\hline Pretreatment score $\mathrm{D}_{1}$ & $5.36 \pm 0.32$ & $5.41 \pm 0.33$ & 0.631 \\
\hline Post treatment score $\mathrm{D}_{15}$ & $5.49 \pm 0.26$ & $5.45 \pm 0.32$ & 0.679 \\
\hline
\end{tabular}

\section{Discussion}

LBP is the commonest presentation of patients reported to the Out Patient Department (OPD) at PM\&R of BSMMU. More than twenty nine thousand patients were treated from July 2008 to December 2008 in the Department of PM\&R, BSMMU, Dhaka, Bangladesh. Among them LBP was the presenting symptoms in $30 \%$ cases and $75 \%$ of those patients suffering from acute LBP. The mean age of the present study group was $38.5 \pm 9.01$ years. Middle age patients were more susceptible to acute LBP. In a study conducted in IPGM\&R, Moyeenuzzaman ${ }^{16}$, observed that $25.55 \%$ patients were suffering from LBP. In 2005 Shahadat ${ }^{17}$, found that among the total patients seen in Physical Medicine Rehabilitation Department, 20\% presented with LBP. That means one fourth to one fifth of all patients was suffering from LBP. The percentage is increasing day by day. In present study male female ratio was $1.4: 1$; in another study done in BSMMU by Shahadat ${ }^{17}$ male female ratio was observed to be $1.33: 1$. In this series service holders $(34.48 \%)$ were affected more followed by daily labourer (18.96\%), housewives (17.24\%), students $(15.52 \%)$, business man $(8.62 \%)$ and driver $(3.46 \%)$. In other series, study by Shahadat ${ }^{17}$ found $1.9 \%$ housewives, $24.2 \%$ service holders, $12.1 \%$ students, $11 \%$ workers, $11 \%$ business men, and farmers $4.4 \%$. Moyeenuzzaman ${ }^{16}$ observed $15 \%$ house wives, $24 \%$ students, $19 \%$ service holders, $13 \%$ farmers, $11 \%$ workers were affected. The 
distribution of occupations was representative of the other local statistics. According to WHO technical LBP is common among occupation that requires prolonged standing. In the present series, $22(39.65 \%)$ patients suffered from muscle strain, 13 (22.41\%) patients from non specific LBP, prolapsed lumbar intervertebral disc in 10 $(17.24 \%)$ cases, lumbar spondylosis in $8(13.79 \%)$ cases and sciatica in $4(6.91 \%)$ patients. In a study done by Shahadat ${ }^{17}, 91$ patients $(68.1 \%)$ were diagnosed as nonspecific LBP, $19.8 \%$ were lumbar spondylosis, $4.4 \%$ patients were unilateral sacralisation, $4.4 \%$ were PLID and $2.2 \%$ were spondylolisthesis.

In this study, subjective pain intensity ${ }^{13}$, visual analog scales $^{13}$ and tenderness index ${ }^{14}$ were decrease in group A patients treated with TENS than group B patients. Disability due to pain ${ }^{14}$ was slight in patients treated with TENS. Modified Schober's test ${ }^{15}$ was $<6 \mathrm{~cm}$ in all patients of group A \& B. Subjective pain intensity, visual analog scales, tenderness index and disability due to pain in the post treatment for group A and B were significantly $(p<0.05)$ better than pretreatment. In another study done by Bertalanffy et $\mathrm{al}^{19}$ observed a significant $(\mathrm{p}<0.01)$ acute pain reduction during transport of patients treated by TENS. In other study done by Maayah ${ }^{20}$ a significant $(p=0.01)$ reduction of acute pain due to musculoskeletal disorders at the end of follow up assessment was observed. The results of the meta-analysis done by Milne et al presented no evidence to support the use of TENS in the treatment of chronic low back pain ${ }^{21}$. Two small studies produced inconclusive results, with a trend toward improvement with TENS and in chronic back pain, there is conflicting evidence regarding its ability to help relieve pain $^{22}$.

The patient improvement and compliance was more in group A treated with TENS. In this group out of 30 patients 24 patients $(80 \%)$ got improved. In group B out of 28 patients 18 patients $(64.28 \%)$ were improved. According to Johnson, the time from the start of stimulation to the onset of analgesia varies from almost immediate to hours (on average, 20-30 minutes in over $75 \%$ of patients and 1 hour in $95 \%$ of patients $)^{23}$. In the present series, $80 \%$ of patient had analgesia within 30 minutes. This result correlates with study of Ordog, who proved that TENS was effective as a combination of acetaminophen and codeine in the treatment of acute pain ${ }^{24}$.

\section{Conclusion}

TENS is the appropriate treatment for acute LBP which cannot be treated less expensively, more safely or more effectively by other means. From this present study it may be concluded that effect of TENS on patients with acute LBP is beneficial. Special attention should be given to the risks and benefits of long-term use, which more appropriately addresses the realities of managing acute LBP.

\section{References}

1. Hart LG, Deyo RA, Cherkin DC. Physician office visits for low back pain. Frequency, clinical evaluation, and treatment patterns from a US National Survey. Spine 1995;20:11-9.

2. Casey PJ, Weinstein JN. Low back pain. In : Ruddy S, Jr EDH, Sledge CB, editors. Kelley's Text book of Rheumatology. PhiladelphiaLondon: WB Saunders; 2001.p. 509-524.

3. Frymoyer JD. Back pain and sciatica. N Engl J Med 1998; 318 : 291 300 .

4. Waddle G. Simple low back pain rest or active exercise? Ann Rheum Dis $1993 ; 52: 317-19$.

5. Simmonds M, Harding V, Watson P, Claveau Y. Physical therapy assessment: expending the model. Pain Res Manage 2000; 16:1013-28.

6. Patel T, Abna A. Diagnosis and Management of acute low back pain. American Academy 2000;39:2-13.

7. Lahad A, Malter AD, Berg AO, Deyo RA. The effectiveness of Four interventions for the prevention of Low Back Pain. JAMA 1994;272:1286-1291

8. Spitzer WO. Scientific approach to the assessment and management of activity-related spinal disorders. A monograph for clinicials. Report of the Quebec Task Force on Spinal Disorders. Spine 1987;12 (suppl 1): S1-S59.

9. Bigos S. Acute low backproblems in adults: assessment and treatment. Agency for Health Care Policy and Research. Clin Pract Guide Quick Ref Guide Clin 1994;1:1-25.

10. Basford J. Electrical Therapy. Krusens Handbook of Physical Medicine and Rehabilitation. 4th ed. Oxford: Oxford University Press; 1987.p.375 - 380 .

11. Thorsteinsson G, Stonnington HH, Stillwell GK, elveback Lr. The placebo effect of transcutaneous electrical stimulation. Pain 1978;5:3141

12. Marchand S, Charest J, Li J, Chenard JR, Lavignolle B, Laurencelle L. Is TENS purely a placebo effect? A controlled study on chronic low back pain. Pain 1993;54:99-106.

13. Von Korff M, Jensen MP, Karoly P. Assessing global pain severity by self report in clinical and health services research. Spine 2000; 25(24):3140-3151

14. Tennen H, Affleck G. Benefit finding and benefit reminding. In: Snyder CR Lopez SJ, eds. Handbook of positive psychology. Fifth Edition. Oxford: Oxford University Press; 2002:584-597.

15. McRac R. Clinical orthopaedic examination: Thoracic and lumbar spine. 5th ed. United Kingdom: Churchill Livingstone; 1997.p.149.

16. Moyeenuzzaman M.A study on the patients with low back pain attending Physical Medicine Department of IPGMR (Dissertation). Dhaka: IPGM\&R; 1992.p.70-115.

17. Shahadat M. A Comparative Study of the Effects of UST and SWD on the patients with chronic low back pain (Dissertation). Dhaka: BCPS; 2005.p.68-124.

18. Deyo RA, Walsh NE, Martin DC, Schoenfeld LS, Ramamurthy S. A controlled trial of transcutaneous electrical nerve stimulation (TENS) and exercise for chronic low back pain. N Engl J Med 1990; 322:162734.

19. Bertalanffy A, Kober A, Bertalanffy $P$ et al. Transcutaneous electrical nerve stimulation reduces acute low back pain during emergency transport. Acta Emerg Med 2005 Jul:12(7):607-11.

20. Maayah M, Al-Jarrah M. Evaluation Transcutaneous electrical nerve stimulation as a treatment of acute neck pain due to musculoskeletal disorders. J Clin Med Res 2010 May 19:2(3):127-36.

21. Milne S, Welch V, Brosseau L, Saginur M, Shea B, Tugwell P, Wells G. Transcutaneous electrical nerve stimulation (TENS) for chronic low back pain. Cochrane Database Syst Rev 2001;(2):CD003008.

22. Glossary. Low back pain. e Medicine Health 2012 January 9 : 1-15.

23. Johnson MI, Ashton CH, Thompson JW. An in-depth study of longterm users of transcutaneous electrical nerve stimulation (TENS). Implications for clinical use of TENS. Pain 1991 March; 44(3):221-9.

24. Ordog GJ. Transcutaneous electrical nerve stimulation versus oral analgesic: a randomized double-blind controlled study in acute traumatic pain. Am J Emerg Med 1987; 5:6-10. 